\title{
Influence of Oxygen Flow Rate on Sputter Deposition Rate and SEM Image of Copper Oxide Thin Films
}

\author{
NAFARIZAL Nayan ${ }^{1 a}$, JIA WEI Low $^{1}$, MOHD ZAINIZAN Sahdan ${ }^{1}$, \\ MOHD KHAIRUL Ahmad ${ }^{1}$, ALI YEON Md Shakaff ${ }^{2}$, AMMAR Zakaria², \\ and AHMAD FAIZAL Mohd Zain ${ }^{3}$ \\ ${ }^{1}$ Microelectronic and Nanotechnology - Shamsuddin Research Centre (MiNT-SRC), \\ Universiti Tun Hussein Onn Malaysia, 86400 Parit Raja, Batu Pahat, Johor, Malaysia \\ ${ }^{2}$ Centre of Excellence for Advanced Sensor Technology, Universiti Malaysia Perlis, \\ 02600 Arau Perlis, Malaysia \\ ${ }^{3}$ Faculty of Manufacturing Engineering, Universiti Malaysia Pahang, \\ 26300 Gambang Kuantan, Pahang Darul Makmur, Malaysia \\ anafa@uthm.edu.my
}

Keywords: copper oxide, thin film, magnetron sputtering deposition

\begin{abstract}
Recently, copper oxide thin film has been studied because of its low cost, sensitivity to ambient condition and easiness to produce oxide thin film. It is one of the p-type semiconductor oxides materials that are suitable to be used as gas sensing material. In order to improve the sensitivity and to optimize the properties of copper oxide thin film, it is essential to study the physical structure of copper oxide. In current studies, copper oxide thin film has been deposited by RF magnetron sputtering at different substrate bias voltages and oxygen flow rates. The results reveal that the deposition rate decreased when the oxygen flow rate above $4 \mathrm{sccm}$. SEM image reveal that nanostructure copper oxide was also obtained when the oxygen flow rate was above 4 sccm. On the other hand, no significant effect on the substrate bias voltage toward the sputter deposition rate was observed.
\end{abstract}

\section{Introduction}

Copper oxide thin film is one of the promising candidates to replace the rare and expensive material such as $\mathrm{SnO}_{2}$ and $\mathrm{In}_{2} \mathrm{O}_{3}$ for applications such as dye sensitized solar cell, photo catalysis, photo chromic devices and gas sensing devices [1]-[4]. Generally, copper oxide is a p-type semiconducting material due to the copper vacancies. However, there has been reports of n-type copper oxide, indicating an interesting tune ability of copper oxide thin films [5], [6]. As a gas sensing device, p-type oxide has advantage of long-term stability because of their tendency to exchange oxygen easily with air. However, due to lack of charge carrier mobility, their sensitivity may become disadvantage. In order to overcome disadvantage, optimum film morphology and electrode configuration are desired.

To date copper oxide thin films have been deposited and growth using several methods, such as radio frequency (RF) magnetron sputtering, chemical vapor deposition, sol-gel and pulsed laser deposition [7]-[9]. Among those techniques, RF magnetron sputtering is a potential method to deposition of copper oxide thin film with high deposition rates and uniformity [10]. In addition, RF magnetron sputtering techniques is good in repeatability performance [11]. In sputtering deposition, the characteristic of the deposited thin film are influenced by the deposition parameter such as oxygen flow ratio, sputtering power, working pressure, deposition time and substrate bias voltage.

In this paper, we report the investigation on the deposition rate and physical characteristic of the copper oxide thin film deposited by RF magnetron sputtering at different substrate bias voltages and oxygen flow rates. The thickness, grain size, and surface morphology of sputtered copper oxide thin films were observed by field emission-scanning electron microscope (FE-SEM). 


\section{Experimental details}

Copper oxide thin film was deposited using reactive RF magnetron sputtering plasma. The magnetron sputtering source was a conventional system that is made of cylindrical permanent magnets attached to an indirect water cooling system. The copper oxide thin films were deposited on 4 inches p-type silicon wafer at a distance of $13 \mathrm{~cm}$ from the target. The silicon wafer was oxidized to form $1 \mu \mathrm{m}$ thick $\mathrm{SiO}_{2}$ layer as the insulator. The sputter target is a 3 inches pure (99.99\% purity) copper target. By using a pure copper target, one can easily control the stoichiometric of deposited thin film using the oxygen-to-argon ratio. The sputter chamber was evacuated to base pressure of $5 \times 10^{-6}$ Torr using vacuum turbo pump and backed by rotary pump. The required sputtering gas (argon, Ar) and reactive gas (oxygen, $\mathrm{O}_{2}$ ) were admitted into the chamber by using the mass flow controller which is attached to the top of the vacuum chamber. During the deposition, Ar flow rate and total chamber pressure were fixed at $50 \mathrm{sccm}$ and 22.5 mTorr, respectively. Sputtering plasma was produced by a $13.6 \mathrm{MHz}$ RF magnetron discharges with an automated matching network. The RF discharge power was fixed at $400 \mathrm{~W}$. A summary of the parameter used during the deposition of copper oxide thin film was tabulated in table 1.

Series of samples were prepared at substrate dc bias voltage ranging from 0 to $-100 \mathrm{~V}$. While the $\mathrm{O}_{2}$ flow rates were varied from 0 to $16 \mathrm{sccm}$. The deposition time was at 4 minutes for all samples. During deposition, the total chamber pressure was controlled by butterfly valve in front of the turbo molecular pump. The deposition process was done at room temperature where no additional heating was introduced to the substrate holder.

Two major techniques were employed to evaluate the properties of copper oxide thin film. Thickness of copper oxide thin film was analyzed from the thin film cross-sectional image taken by FE-SEM (JEOL, JSM-7600F Series). Deposition rate was calculated from the thickness divided by the deposition time. Surface morphology and roughness of the films were observed by FE-SEM. A probe voltage and current of $5 \mathrm{kV}$ and $7 \mathrm{~mA}$, respectively were used when analyzed using FESEM. Magnification of 50,000 was used to evaluate the changes of the grain size with different deposition parameters.

\section{Results and discussion}

Figure 1 shows the deposition rate of thin films at various substrate bias voltages and oxygen flow rates. At $0 \mathrm{sccm}$ of oxygen flow rate, the deposition is totally a metal copper deposition. At this point the deposition rate is approximately $40 \mathrm{~nm} / \mathrm{min}$. This is comparably high for RF magnetron sputtering deposition. Note that in general, deposition rate for RF magnetron sputtering is lower when compared to de magnetron sputtering. However, to growth a metal oxide thin film, it is essential to use RF magnetron sputtering.

Table 1. Condition for copper oxide thin film deposition.

\begin{tabular}{ll}
\hline Oxygen flow rate & $0,4,8,16 \mathrm{sccm}$ \\
Substrate bias voltage & $0,-40,-60,-100 \mathrm{~V}$ \\
Target size & 3 -inch copper target \\
Substrate temperature & Room temperature \\
Target-substrate distance & $13 \mathrm{~cm}$ \\
Working pressure & $22.5 \mathrm{mTorr}$ \\
RF dissipation power & $400 \mathrm{~W}$ \\
Argon flow rate & $50 \mathrm{sccm}$ \\
Deposition time & $4 \mathrm{mins}$ \\
\hline
\end{tabular}

When $\mathrm{O}_{2}$ gas was introduced into the deposition chamber, deposition rate slightly increased at 4 sccm and then continue to decreased at oxygen flow rate above $4 \mathrm{sccm}$. When $\mathrm{O}_{2}$ gas is introduced into the chamber, the sputtering plasma become weaken and thus reduce the sputtering yield of target materials. As a result, the deposition rate decreased. However, at $4 \mathrm{sccm}$ of $\mathrm{O}_{2}$ one can clearly 
seen a so-called guttering effect where the pure copper target surface was poisoned and their sputtering yield by Ar ions changed [12]. On the other hand, the effect of substrate bias voltage toward the deposition rate was not significant as shown in Fig. 1. The deposition rates at different substrate bias voltages were almost the same.

Figure 2 shows FE-SEM images of copper oxide thin film surface deposited at different oxygen flow rates. The substrate bias voltage was 0 V. Copper thin film in Fig. 2(a) had large crack between its grain structures. The crack reduce when oxygen flow rate is at $4 \mathrm{sccm}$, and small grain of copper oxide can be observed. Note that our X-ray diffraction (XRD) data showed that at $4 \mathrm{sccm}$ of oxygen flow rate, the $\mathrm{Cu}_{2} \mathrm{O}$ (111) peak was detected. At 8 and $16 \mathrm{sccm}$ of oxygen flow rate, the copper oxide thin films become denser with small grain size below than $20 \mathrm{~nm}$. Small grain size is preferable in order to improve the gas sensing surface interaction. We had also confirmed that the gas sensing performance or copper oxide thin films deposited at this parameter showed better sensing respond compared to $4 \mathrm{sccm}$ of oxygen flow rate. The XRD data reveal that at 8 and 16 sccm of oxygen flow rate, $\mathrm{CuO}$ (111) peak was detected.

In addition, the nanostructure of copper oxide thin film in Fig. 2 has also been re-confirmed by AFM analysis. The roughness of copper oxide thin film deposited at $4 \mathrm{sccm}$ of oxygen flow rate was $6.6 \mathrm{~nm}$. It decreased to 4.7 and 2.8 at $8 \mathrm{sccm}$ and $16 \mathrm{scccm}$ of oxygen flow rate, respectively. At higher concentration of oxygen in sputtering chamber, the growth of copper oxide thin film become slower and thus results in nanostructured copper oxide thin film.

\section{Conclusion}

Copper oxide thin film has been successfully deposited using RF magnetron sputtering plasma at various oxygen flow rates and substrate bias voltages. Significant effect of oxygen flow rate toward the deposition rate and physical structure of copper oxide thin film has been observed. Boundary parameter between the sputter target poisoning has been clarified. Grain of copper oxide at nanoscale is believe will improve the gas sensing performance of copper oxide thin film.

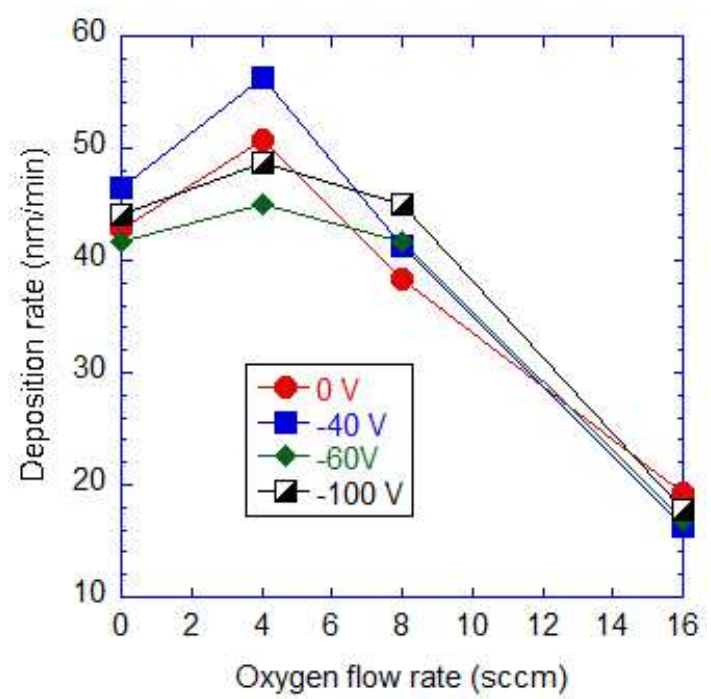

Figure 1. Deposition rate of thin films at various substrate bias voltages and oxygen flow rates. 
(a) $\mathrm{O}_{2}: 0 \mathrm{sccm}$

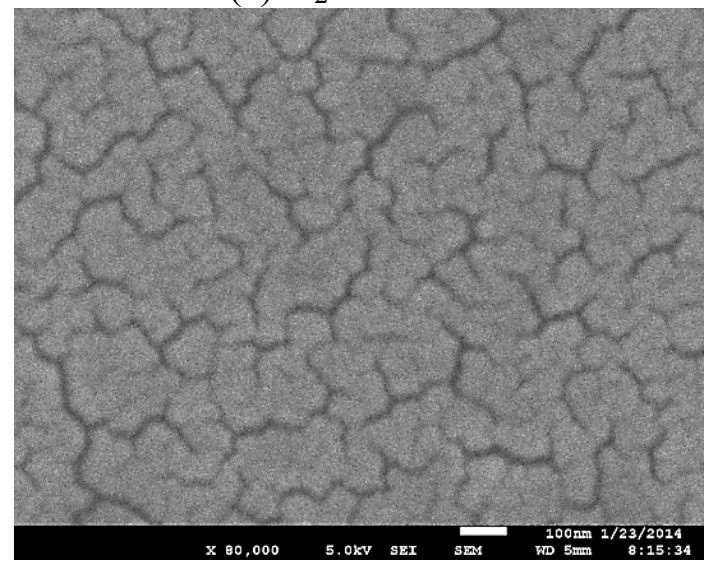

(c) $\mathrm{O}_{2}: 8 \mathrm{sccm}$

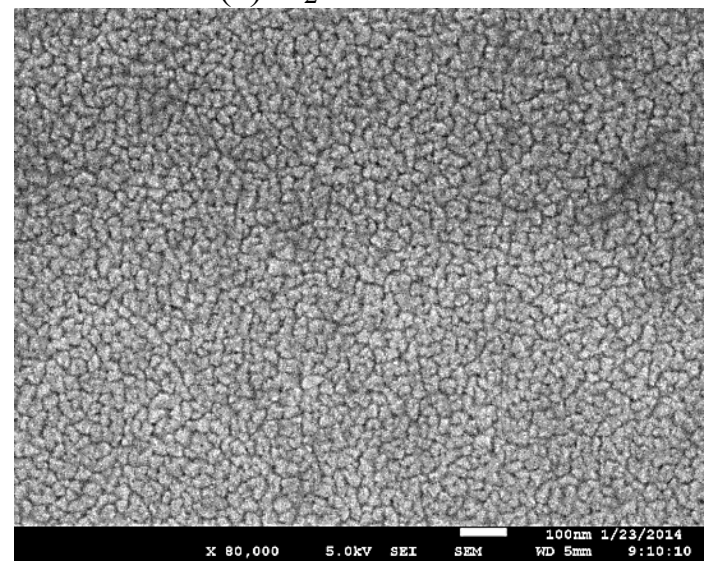

(b) $\mathrm{O}_{2}: 4 \mathrm{sccm}$

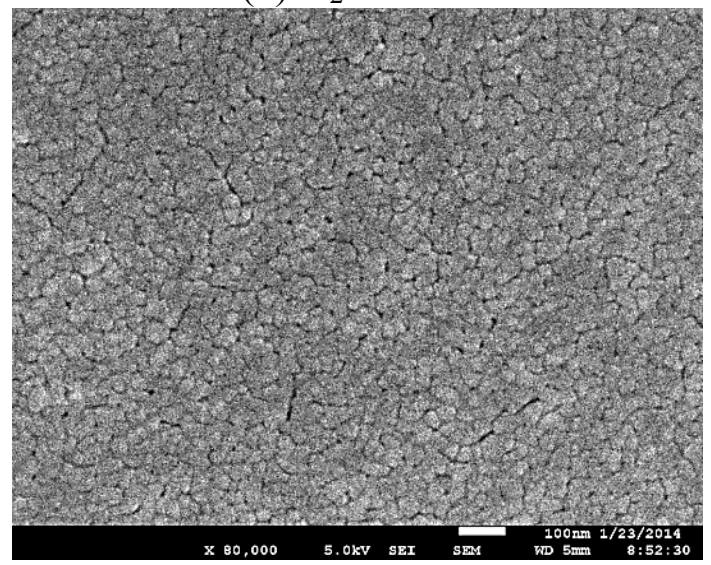

(d) $\mathrm{O}_{2}: 16 \mathrm{sccm}$

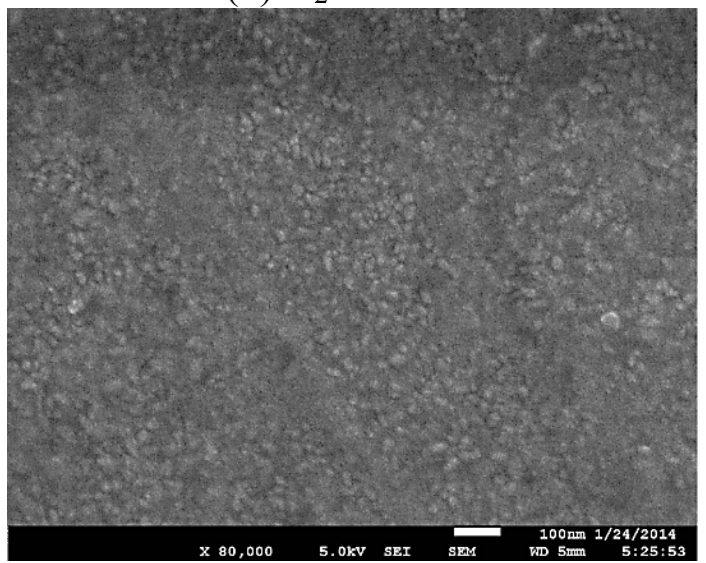

Figure 2. FE-SEM images of copper oxide thin film surface deposited at different oxygen flow rates. The substrate bias voltage was $0 \mathrm{~V}$.

\section{Acknowledgment}

The present work was supported by FRGS, MTUN-COE and Short Term Grant of Universiti Tun Hussein Onn Malaysia. The authors would like to thank Universiti Tun Hussein Onn Malaysia for the financial support through the Post Graduate Incentive Grant (GIPS).

\section{References}

[1] M. Batzill and U. Diebold, The surface and materials science of tin oxide, Prog. Surf. Sci., vol. 79, no. 2-4 (2005) pp. 47-154.

[2] G. Korotcenkov and B. K. Cho, Thin film $\mathrm{SnO}_{2}$-based gas sensors: Film thickness influence, Sensors Actuators B Chem., vol. 142, no. 1, (2009) pp. 321-330.

[3] L. Liao, Z. Zhang, B. Yan, Z. Zheng, Q. L. Bao, T. Wu, C. M. Li, Z. X. Shen, J. X. Zhang, H. Gong, J. C. $\mathrm{Li}$, and $\mathrm{T}$. $\mathrm{Yu}$, Multifunctional $\mathrm{CuO}$ nanowire devices: p-type field effect transistors and CO gas sensors., Nanotechnology, vol. 20, no. 8, (2009) p. 085203.

[4] J. Xu, J. Han, Y. Zhang, Y. Sun, and B. Xie, Studies on alcohol sensing mechanism of ZnO based gas sensors, Sensors Actuators B Chem., vol. 132, no. 1, (2008) pp. 334-339. 
[5] M. Parmar and K. Rajanna, Copper ( II ) oxide thin film for methanol and ethanol sensing, vol. 4, no. 4, (2011) pp. 710-725.

[6] G. Korotcenkov, Metal oxides for solid-state gas sensors: What determines our choice?, Mater. Sci. Eng. B, vol. 139, no. 1, (2007) pp. 1-23.

[7] R. Benzerga and C. Boulmer-leborgne, Epitaxial growth of copper oxide films by reactive cross-beam pulsed-laser deposition, J. Cryst. Growth, vol. 311, (2009) pp. 3352-3358.

[8] M. H. Aslan, The preparation of copper ( II ) oxide thin films and the study of their microstructures and optical properties, Mater. Chem. Phys., vol. 83, (2004) pp. 140-144.

[9] D. Barreca, E. Comini, A. Gasparotto, C. Maccato, C. Sada, G. Sberveglieri, and E. Tondello, Chemical vapor deposition of copper oxide films and entangled quasi-1D nanoarchitectures as innovative gas sensors, Sensors Actuators B Chem., vol. 141, no. 1, (2009) pp. 270-275.

[10] P. Samarasekara, N. T. R. N. Kumara, and N. U. S. Yapa, Sputtered copper oxide (CuO) thin films for gas sensor devices, J. Phys. Condens. Matter, vol. 18, no. 8, (2006) pp. 2417-2420.

[11] A. S. Zoolfakar, M. Z. Ahmad, R. A. Rani, J. Z. Ou, S. Balendhran, S. Zhuiykov, K. Latham, W. Wlodarski, and K. Kalantar-zadeh, Nanostructured copper oxides as ethanol vapour sensors, Sensors Actuators B Chem., vol. 185, (2013) pp. 620-627.

[12] K. Takamura, Y. Abe, and K. Sasaki, Influence of oxygen flow ratio on the oxidation of Ti target and the formation process of $\mathrm{TiO}_{2}$ films by reactive sputtering, Vacuum, vol. 74, no. 3-4, (2004) pp. 397-401. 